\title{
SOME INEQUALITIES RELATING TO UPPER AND LOWER BOUNDS FOR THE RIEMANN-STIELTJES INTEGRAL
}

\author{
S. S. Dragomir and C. E. M. PearCe
}

Abstract. Some new inequalities are obtained relating to the generalized trapezoid and midpoint rules for the Riemann-Stieltjes integral with a convex integrand and monotone nondecreasing integrator. Results are deduced for the special case of weighted Riemann integrals.

Mathematics subject classification (2000): Primary 26D15, Secondary 26D10..

Keywords and phrases: Riemann-Stieltjes integral, trapezoid inequality, midpoint inequality, weighted Riemann integrals, convexity.

\section{REFERENCES}

[1] G.A. Anastassiou, Grüss type inequalities for the Stieltjes integral, Nonlin. Funct. Anal. Appl., 12 (2007), 583-593.

[2] G.A. Anastassiou, Chebyshev-Grüss type and comparison of integral means inequalities for the Stieltjes integral, Panam. Math. J., 17 (2007), 91-109.

[3] N.S. Barnett, W.-S. Cheung, S.S. Dragomir And A. Sofo, Ostrowski and trapezoid type inequalities for the Stieltjes integral with Lipschitzian integrands or integrators, Preprint, RGMIA Res. Rep. Coll. (2006) Article 9. http://rgmia.vu.edu.au/v9n4.html

[4] P. Cerone, W.-S. Cheung And S.S. Dragomir, On Ostrowski type inequalities for Stieltjes integrals with absolutely continuous integrands and integrators of bounded variation, Comput. Math. Appl., 54 (2007), 183-191.

[5] P. Cerone And S.S. DragomiR, New bounds for the three-point rule involving the RiemannStieltjes integral, Advances in Statistics, Combinatorics and Related Areas, 53-62, World Sci. Publ., River Edge, NJ, 2002.

[6] P. Cerone And S.S. Dragomir, Approximation of the Stieltjes integral and applications in numerical integration, Appl. Math., 51 (2006), 37-47.

[7] P. CERone, S.S. DRAGomir AND C.E.M. PeArCe, A generalized trapezoid inequality for functions of bounded variation, Turkish J. Math., 24 (2000), 147-163.

[8] W.-S. Cheung And S.S. Dragomir, Two Ostrowski type inequalities for the Stieltjes integral of monotonic functions, Bull. Austral. Math. Soc., 75 (2007), 299-311.

[9] R. Darst And H. Pollard, An inequality for the Riemann-Stieltjes integral, Proc. Amer. Math. Soc., 25 (1970), 912-913.

[10] S.S. Dragomir, On the Ostrowski's inequality for Riemann-Stieltjes integral, Korean J. Appl. Math., 7 (2000), 477-485.

[11] S.S. DRAGOMIR, An Ostrowski like inequality for convex functions and applications, Revista Math. Complutense, 16 (2003), 373-382.

[12] S.S. DRAGOMIR, Inequalities of Grüss type for the Stieltjes integral and applications, Kragujevac J. Math., 26 (2004), 89-122.

[13] S.S. DRAGOMIR, On the Ostrowski inequality for Riemann-Stieltjes integral $\int_{a}^{b} f(t) d u(t)$ where $f$ is of Hölder type and $u$ is of bounded variation and applications, J. KSIAM, 5 (2001), 35-45.

[14] S.S. DRAGOMIR, Inequalities for Stieltjes integrals with convex integrators and applications, Appl. Math. Lett., 20 (2007), 123-130.

[15] S.S. Dragomir, C. Buse, M.V. Boldea and L. Braescu, a generalization of the trapezoidal rule for the Riemann-Stieltjes integral and applications, Nonlinear Anal. Forum, 6 (2001), 337-351. 
[16] S.S. Dragomir And I.A. Fedotov, An inequality of Grüss' type for Riemann-Stieltjes integral and applications for special means, Tamkang J. Math., 29 (1998), 287-292.

[17] S.S. DRAGOMIR AND I. Fedotov, A Grüss type inequality for mappings of bounded variation and applications to numerical analysis, Nonlinear Funct. Anal. Appl., 6 (2001), 425-438.

[18] Zheng LiU, Refinement of an inequality of Grüss type for Riemann-Stieltjes integral, Soochow J. Math., 30 (2004), 483-489.

[19] P.R. MERCER, Hadamard's inequality and trapezoid rules for the Riemann-Stieltjes integral, J. Math. Anal. Applic., 344 (2008), 921-926.

[20] R.T. Rakhmail, The inverse Chebyshev inequality for Stieltjes integrals, Math. Anal. (Russian), 9-15 Leningrad Gos. Ped. Inst. (1990). 